\title{
A PRELIMINARY COMMUNICATION ON THE DEGENERATION OF THROMBIN IN SERUM OF NORMAL CONTROLS AND OF PATIENTS BEFORE AND AFTER SURGERY
}

\author{
BY \\ C. G. BERRY \\ From St. James' Hospital, Balham
}

(RECEIVED FOR PUBLICATION OCTOBER 28, 1955)

The presence of an antithrombin in normal plasma and serum has been known for many years. In $1892 \mathrm{Schmidt}$ postulated its existence when he observed the rapid disappearance of thrombin from blood after coagulation. Tests have been devised enabling the titre of antithrombin to be determined. Most of these tests depend on the inactivation of serial dilutions of thrombin of known concentration by the antithrombin being investigated; after incubation the specimens are added to fibrinogen and the presence or absence of coagulation observed (Astrup and Darling, 1942 ; Hurn and Mann, 1947 ; Owen and Bollman, 1948 ; Lévy-Solal and Roost, 1952).

Such tests have been used to investigate variations in antithrombin activity of plasma following surgical operations, and attempts have been made to predict the onset of thromboses in these patients. Results have been conflicting, however. Boshamer (1927) demonstrated a fall in the antithrombin titre following operation. Holden, Cole, and Davis (1949) found no change in the uncomplicated postoperative period, but demonstrated a marked fall in titre in those patients undergoing thrombosis. Volkert and Piper (1943) had been unable to show any change during active thrombosis. In a series of patients with thrombosing tendencies investigated by Hurn, Barker, and Mann (1947) low and high antithrombin titres were found in equal numbers, although all the patients who were being treated with dicoumarol showed an increase in serum antithrombin activity. It has been suggested that thrombosis is more likely to occur in the post-operative period when the antithrombin level is low and the prothrombin conversion rate normal (Kay, Hutton, Weiss, and Ochsner, 1950).

This paper describes a test of thrombin degeneration in serum, and the results obtained using this test in normal controls and in a small series of patients who have been examined before and after surgical operation. This work forms part of an investigation into the effects of surgical trauma on the coagulation mechanism, the results of which will be presented more fully in a later communication.

\section{The Thrombin Degeneration Test}

The test was developed as a modification of the prothrombin consumption test; so that the results of these two tests might be compared the quantities of reagents and the techniques used were the same. In all other respects, however, the test is similar to the thrombin generation test described by Macfarlane and Biggs (1953).

Reagents.-Blood was collected into siliconed centrifuge tubes, citrated $(0.1 \mathrm{ml}$. citrate $/ 1.0 \mathrm{ml}$. blood), and the tubes placed in melting ice. After centrifuging at 1,500 r.p.m. for 10 minutes the plasma was separated and kept in melting ice until it was used in the test. It was found that the same readings were obtained whether the plasma was examined immediately or after a delay of several hours.

Approximately $1.0 \mathrm{ml}$. of blood was allowed to clot and the serum collected. This was used as an alternative diluent to saline in the test.

One millilitre of plasma was treated with $0.1 \mathrm{ml}$. of aluminium hydroxide suspension to remove the prothrombin, the mixture being incubated until the " prothrombin" time lay between one and four minutes (Biggs and Douglas, 1953). This alumina plasma was used as an alternative diluent to saline in the test.

Brain thromboplastin was used, prepared by the method described by Biggs and Macfarlane (1953).

Fibrinogen was provided by the Lister Institute. Each ampoule was made up with $10 \mathrm{ml}$. of saline, and $a 1$ in 8 dilution made from this. Variations in the concentration of fibrinogen between 1 in 4 and 1 in 16 did not affect the clotting times, but on either side of this range the clotting time rapidly increased (Fig. 1). 


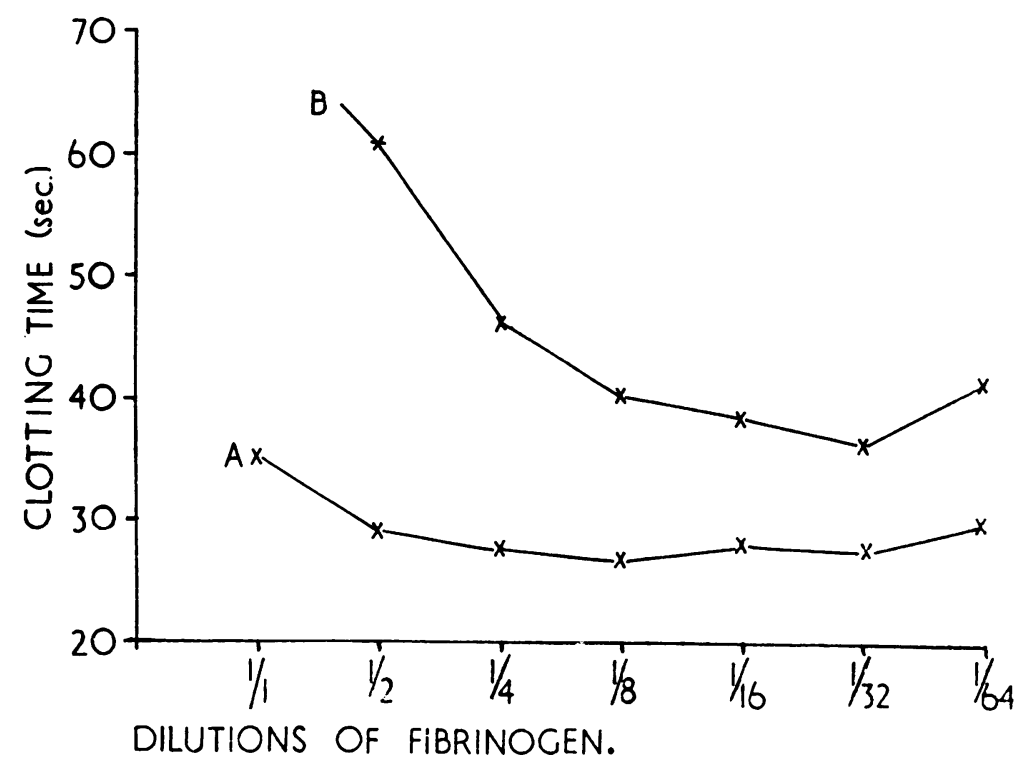

FIG. 1.-Graph showing the effect of varying the dilutions of fibrinogen used in the thrombin degeneration test. The $1 / 1$ dilution is equivalent to an ampoule of fibrinogen made up with $5 \mathrm{ml}$. of saline. $A=$ curve using 30 -second-old serum. $B=$ curve using 90 -second-old serum.

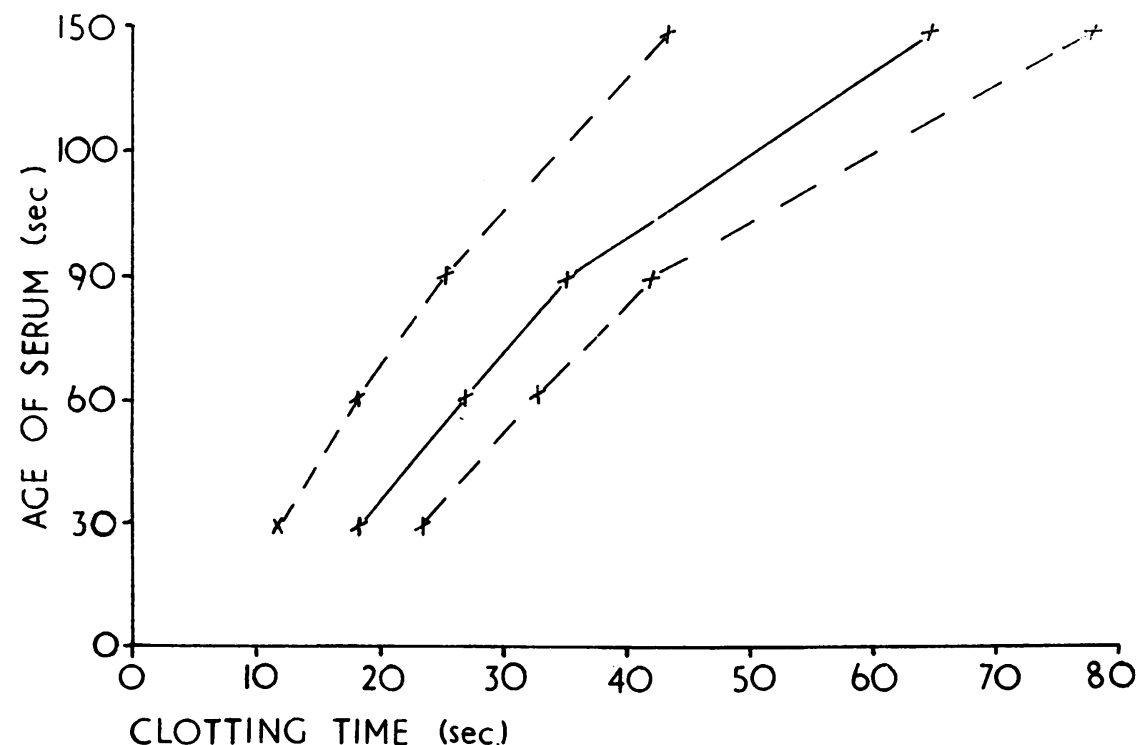

FIG. 2.-Graph showing the rate of dezeneration of thrombin in normal serum. The centre curve represents the average of the results, all of which fell between the two outer curves.

Technique of Test.-Into each of four tubes placed in a water-bath at $37^{\circ} \mathrm{C}$. is pipetted $0.4 \mathrm{ml}$. of fibrinogen. Into a fifth tube is pipetted $0.2 \mathrm{ml}$. of plasma and $0.2 \mathrm{ml}$. of saline. To this is added $0.2 \mathrm{ml}$. of brain thromboplastin and the mixture is recalcified with $0.2 \mathrm{ml}$. of $0.25 \%$ calcium chloride solution. A glass hook is used to agitate the contents of the tube, and as soon as fibrin is deposited on the hook a stop- watch is started. The fibrin clot is immediately removed after expressing the serum from it. At intervals of $30,60,90$, and 150 seconds after coagulation $0.1 \mathrm{ml}$. of the mixture is removed and added to the fibrinogen, the clotting times being noted.

Whenever sufficient plasma was available the test was repeated substituting $0.2 \mathrm{ml}$. of either alumina 
plasma or serum in place of the saline, or using $0.4 \mathrm{ml}$. of undiluted plasma.

The 20 patients included in this series were taken at random from those who were admitted to hospital for surgical operation. Specimens of blood were taken from these patients before operation and at repeated intervals after operation for as long as they remained in hospital. The operations performed were : partial gastrectomy, 12 cases; cholecystectomy, three cases ; vagotomy, pyloroplasty, and appendicectomy, two cases; nephrectomy, one case; thyroidectomy, one case ; appendicectomy, one case. In none of these patients was the post-operative period complicated by venous thrombosis.

\section{Results}

Thrombin Degeneration in Normal Serum.The test was carried out on specimens of normal plasma obtained from members of the laboratory staff and from "well" surgical patients immediately after their admission to hospital. When different specimens of blood were taken from the same individual over a period of time (up to two weeks) there was no significant variation between readings obtained on different days. The results are shown in Fig. 2. It will be seen that serum taken 30 seconds after coagulation contained sufficient thrombin to bring about clotting of the fibrinogen in 12 to 25 seconds (average reading 19 seconds). With increasing age of the serum the amount of thrombin diminished, so that 150 seconds after the plasma had clotted the average coagulation time of the fibrinogen was 64 seconds, and in most cases all thrombin had disappeared after four minutes.

Using serum in place of the saline as a diluent for the plasma resulted in a marked increase in the clotting time of the fibrinogen, and this increase was greater still if alumina plasma was used. Presumably during coagulation of blood there is a partial utilization of the plasma antithrombin, the titre in serum being lower than in the original plasma. When $0.4 \mathrm{ml}$. of undiluted plasma was used in the test the fibrinogen clotting time shortened initially, quickly followed by a return to normal and finally by a prolongation. In this latter experiment, although the amount of antithrombin present in the mixture is doubled, so also is the amount of prothrombin; the increased rate of thrombin generation which results must initially overpower the antithrombin activity of the plasma. Results from a typical case are shown in Table I.

Specimens of alumina plasma stored in the icebox of the refrigerator showed no loss of antithrombin titre, and it was found possible to keep frozen specimens and compare them with fresh specimens taken at a later date.
TABLE I

CLOTTING TIMES OF FIBRINOGEN WITH SPECIMENS OF SERUM AFTER COAGULATION USING UNDILUTED PLASMA AND PLASMA DILUTED WITH SALINE, SERUM, AND ALUMINA PLASMA

\begin{tabular}{|c|c|c|c|c|}
\hline $\begin{array}{c}\text { Age of } \\
\text { Serum } \\
\text { after } \\
\text { Coagulation } \\
\text { (Sec.) }\end{array}$ & $\begin{array}{c}\begin{array}{l}0.4 \mathrm{ml} . \\
\text { Plasma } \\
\text { (Undiluted) }\end{array} \\
\text { (Sec.) }\end{array}$ & $\begin{array}{l}0.2 \mathrm{ml} . \\
\text { Plasma } \\
0.2 \mathrm{ml} . \\
\text { Saline } \\
\text { (Sec.) }\end{array}$ & $\begin{array}{c}0.2 \mathrm{ml} . \\
\text { Plasma } \\
0.2 \mathrm{ml} \text {. } \\
\text { Serum } \\
\text { (Sec.) }\end{array}$ & $\begin{array}{c}0.2 \mathrm{ml} . \\
\text { Plasma } \\
0.2 \mathrm{ml} . \\
\text { Alumina } \\
\text { Plasma } \\
\text { (Sec.) }\end{array}$ \\
\hline $\begin{array}{r}30 \\
60 \\
90 \\
150 \\
210\end{array}$ & $\begin{array}{r}9 \\
16 \\
24 \\
66 \\
120\end{array}$ & $\begin{array}{l}17 \\
20 \\
25 \\
40 \\
95\end{array}$ & $\begin{array}{r}20 \\
30 \\
60 \\
90 \\
150\end{array}$ & $\begin{array}{c}22 \\
40 \\
90 \\
190 \\
300 \pm\end{array}$ \\
\hline
\end{tabular}

Thrombin Degeneration During Post-operative Period.-Every one of the 20 patients who were examined before and after operation showed a markedly increased rate of thrombin degeneration during the post-operative period. This change began on the first or second day after operation, and reached its maximum between the fourth and seventh day. The rate of thrombin degeneration returned to the pre-operative level between the tenth and fourteenth day after operation. The readings from one patient (Case 15; partial gastrectomy) are shown in Fig. 3, and in Fig. 4 is shown the marked shift to the right of the graph during the post-operative period. By repeating the test using alumina plasma and comparing this with (a) alumina plasma from a normal control and $(b)$ previous specimens of alumina plasma from the same patient which had been stored in the refrigerator, it was demonstrated that the difference between pre- and post-operative readings was not the result of technical errors or the use of different preparations of fibrinogen.

\section{Discussion}

Following the initiation of blood coagulation there is a rapid generation of thrombin from prothrombin, far in excess of the amount actually required. The excess thrombin is removed from the plasma in two ways: by adsorption on to the fibrin clot, and by its neutralization by plasma antithrombin. In the test described in this paper the fibrin clot is removed from the serum immediately after its formation, and it is believed that only the antithrombin mechanism is involved in the subsequent degeneration of thrombin. Any differences in the results of the test, when comparing either specimens of plasma from different patients or different specimens from the same patient, must therefore reflect different titres of antithrombin (the rate of prothrombin conversion being normal in every case). All of the surgical patients 


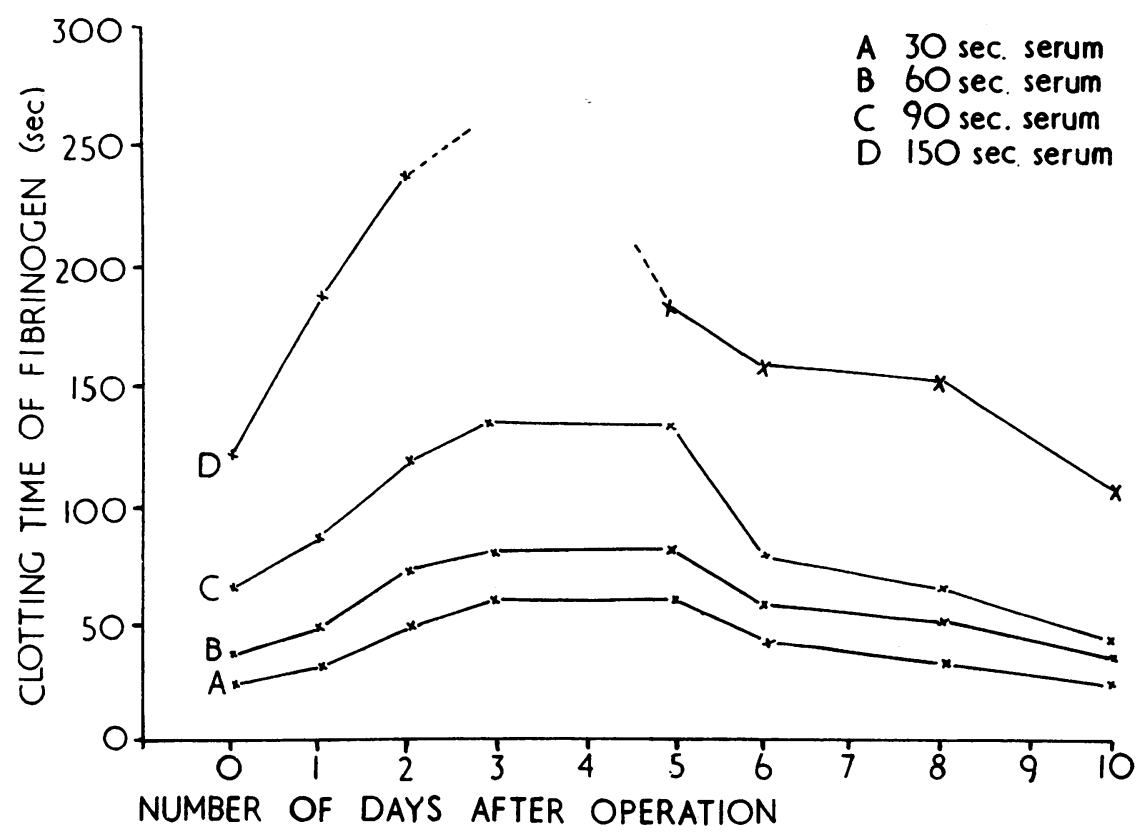

FIG. 3.-Results of thrombin degeneration test at intervals after operation. The four curves represent the fibrinogen clotting times using serum $30,60,90$, and 150 seconds after coagulation of the patient's plasma. Between the second and fifth day the clotting times of curve $D$ were so prolonged that accurate readings were not possible.

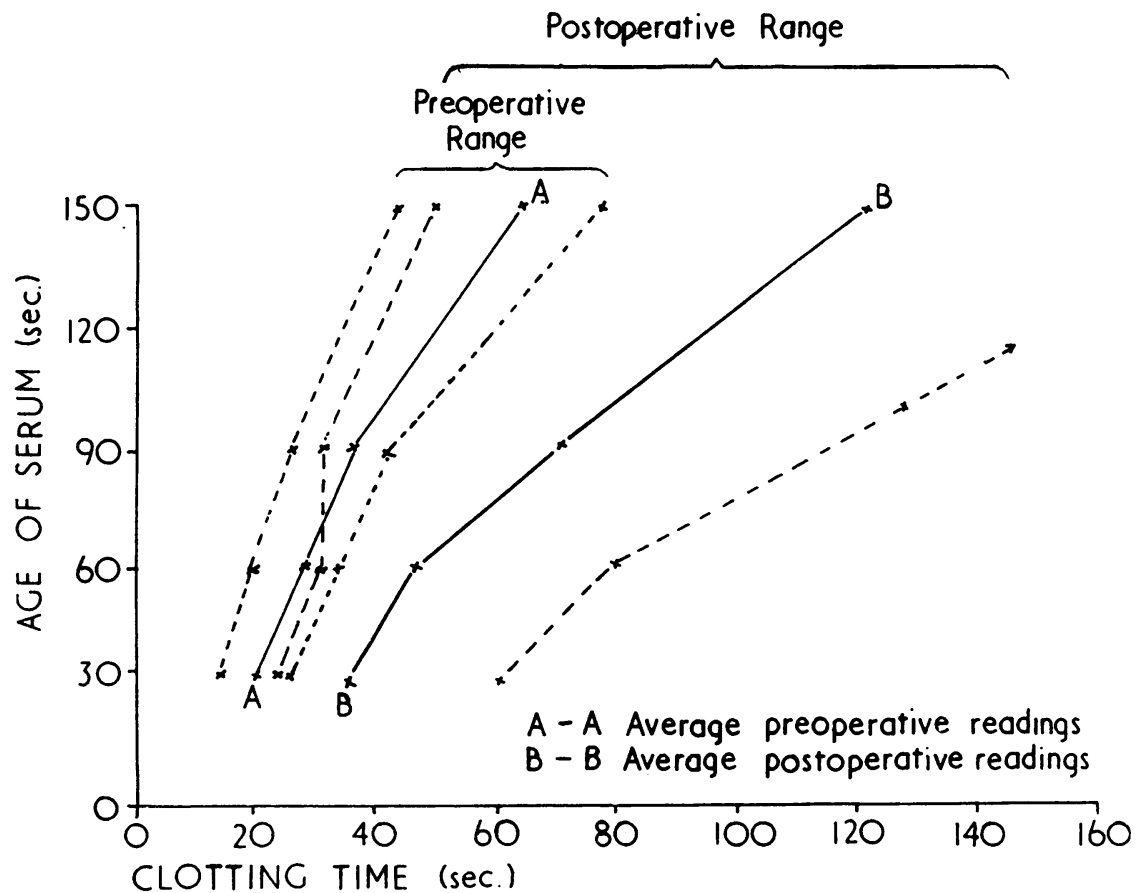

Fig. 4.-Pre-operative and maximum post-operative readings of thrombin degeneration test. 
examined showed a more rapid removal of thrombin following operation, reaching a maximum about one week after operation and returning to normal again after the second week. These results suggest that a raised level of plasma antithrombin may be a normal sequel to trauma, limiting blood clotting to the site of injury and preventing thromboses elsewhere.

\section{Summary}

A test of thrombin degeneration in serum is described.

This test has been employed in a series of normal controls and in 20 surgical patients who were examined before and at repeated intervals after operation. The results are described.

All of the surgical patients showed an increased rate of thrombin degeneration following operation, reaching a maximum between the fourth and seventh day, and returning to normal between the tenth and fourteenth post-operative day.

These results are believed to be due to a raised titre of plasma antithrombin during the postoperative period, and it is suggested that this is the normal response of the body to trauma of any kind.

I wish to thank the surgical and nursing staff of St. James' Hospital for their co-operation in these investigations, and especially Mr. N. C. Tanner and Mr. A. M. Desmond, under whose care these patients were admitted. I would also like to thank Dr. G. T. Allen for his advice and assistance and for reading the manuscript.

\section{REFERENCES}

Astrup, T., and Darling, S. (1942). Acta physiol. scand., 4, 293.

Biggs, R., and Douglas, A. S. (1953). Journal of Clinical Pathology, 6, 23.

- and Macfarlane, R. G. (1953). Human Blood Coagulation and Its Disorders, 1st ed., p. 54. Blackwell, Oxford.

Boshamer, K. (1927). Klin. Wschr., 6, 740.

Holden, W. D., Cole, J. W., and Davis, J. H. (1949). Surg. Gynec. Obstet., 89, 20.

Hurn, M., Barker, N. W., and Mann, F. D. (1947). Amer. J. clin. Path., 17, 709.

— and Mann, F. D. (1947). Ibid., 17, 741.

Kay, J. H., Hutton, S. B., Weiss, G. N., and Ochsner, A. (1950). Surgery, 28, 24.

Lévy-Solal, E., and Roost, W. (1952). Rev. Hémat., 7, 250.

Macfarlane, R. G., and Biggs, R. (1953). Journal of Clinical Pathology, 6, 3 .

Owen, C. A., and Bollman, J. L. (1948). Proc. Soc. exp. Biol. (N.Y.), 67, 367 .

Volkert, M., and Piper, J. (1943). Acta chir. scand., 89, 417. 